\title{
Pursuing Sustainability via Reverse Logistics: The Symbiosis Effect Between the Local Authorities and Householders
}

\author{
Emy E. A. Jalil \\ School of Technology Management and Logistics \\ UUMCOB, 06010 University of Utara Malaysia \\ Hull University Business School, University of Hull \\ E-mail: ezura@uum.edu.my
}

\begin{abstract}
This paper reveals how factors associated with household recycling systems affect household recycling behaviour, and how household recycling behaviour affects the provision of household recycling systems by the local authorities (LA). The main objective is to reveal and explain the interaction and symbiosis effects between household recycling system and household recycling behaviour. Using a mixed methodology stance, the first approach is a qualitative research stage supported the symbiosis effect between the LAs and the householders. The second approach is quantitative research stage employed multiple regression analysis that juxtaposed the existence of interactions between personal factors and situational factors which the representation of LAs and the householders respectively. Finally, co-examination between the first and second stages revealed the need to use symbiosis effect perspective in understanding backward movement between householders and household recycling waste systems. This study has found that a "symbiosis effect" perspective appears to be a robust framework to bring together effective household waste recycling systems and sustainable development considerations to enhance both sustainability and the economy. Further, the study provides empirical evidence examining both situational and personal factors of households and their interactions, which were previously not well-understood. This study has incorporated behavioral aspects in the reverse logistics process that should help improve the LAs' planning processes.
\end{abstract}

Keywords: reverse logistics, household recycling, waste management, local authority, symbiosis

\section{INTRODUCTION}

The growing number of pressures from policymakers and state agencies across the globe has motivated stakeholders to increase the recycling rate among householders and to divert most of the waste from landfill. In particular, municipal solid waste (MSW) is presently and has been an environmental issue since the beginning of the industrial era (Dimitrova, 2014).

The logistics literature has had a significant interest in matters of sustainable and green logistics for some time (Grant et al., 2015). Much work has also been done on reverse logistics (RL) concepts since the late 1990s (Carter and Ellram, 1998) and these concepts are also considered a crucial element in green supply chain management (Hazen et al., 2011). In addition, this study adopted Tibben-Lembke and Rogers' definition of RL for this study as "the movement of product or materials in the opposite direction for the purpose of creating or recapturing value, or for proper disposal" (2001: 271).

One under-investigated area in RL is how to deal with 'end-of-life' or 'end-of-use' goods (Bing et al., 2014; Xie and Breen, 2014), particularly regarding recycling or disposal of them (Mishran et al., 2012). Wright et al., (2011: 10) suggest that "little attention has been given to the best methods to develop overall recycling channels". However, the significant attention to the recycling and management of waste has followed the increasing dominance of end-of-life take-back laws (Toffel, 2003); e.g. the European Union's waste electrical and electronic equipment (WEEE) directive that stipulates all such goods must be recycled and not disposed (Grant et al., 2015). The management of HRWS recycling can be defined as:

"...the process of systematically collecting, sorting, decontaminating and returning of waste materials to commerce as commodities for use or exchange" (Wiard and Sopko, 1991: 3)

The paper intention is to unfold that households have a critical role in determining whether end-of-life goods are captured by an RL system or are disposed of as waste. This is especially true for mundane household waste items such as food and beverage packaging, as opposed to the more durable electronic items covered by take-back regulations. However, LA waste systems are relatively neglected in the RL literature compared to commercial RL systems. Similar to other suppliers, an LA must treat consumers and/or households as an external element in an exchange relationship. However, there is no direct association of cost and service: financial penalties and rewards are not usually applied to households to incentivize recycling behaviour. The question becomes how to motivate them to separate waste, which is cheaper for LAs than the post-source separation of co-mingled waste, but risks lower participation rates. A range of logistics design factors influence recycling behaviour (i.e., the situational factors), which controlled by the LA and which influences the extent to which customers or households comply. These can also be considered 'hard' factors that can be quantified and measured (Caplice and Sheffi, 1994).

Hence, previous empirical studies have not explicitly revealed the conjuncture between recycling behaviour and logistical designs; have the possibility of impacting the recyclables streams. Strategically, physical aspects affect 
the degree to which consumers can be motivated to create multiple streams of separated recyclables, with the alternative being a single stream or a fully co-mingled supply of recyclables (Abbott et al., 2011).

\section{LITERATURE REVIEWS}

\subsection{Sustainability and Reverse Logistics}

Sustainability has become an important concept for twenty-first-century organizations (Abbasi and Nilsson, 2012) and in response to this, many organizations have to endure pressures from multiple stakeholders to be able to manage and sustain their economic activities (Grant, et al., 2015). Some of these organizations decided to employ strategic supply chain management which emphasizes reverse logistics (RL) within their organizations to pursue such sustainability (Grant, et al., 2015).

In recent years, the reason for $\mathrm{RL}$ to emerge as a position in the value chain is due to the consequence of a growing number of environmental regulations (Large et al., 2013) in many parts of the world. Initially, these regulations are enforced to manufacturers or producers on disposition of certain products (WEEE and packaging waste examples from Mayers and Butler, 2013) then the enforcement is subsequently extended to the householders especially in separating WEEE from their waste channel and disposing them to designated drop-in facility (Mayers \& Butler, 2013). These directives are not restricted to householders alone, but also to both companies and municipalities to be committed to enforcing the regulations (Barba-Gutiérrez et al., 2008).

In accordance with EU waste directives (Directive 2008/98/EC); the waste legislation should be in any ways to reduce the implication of waste generation and management towards community well-being and surroundings. The strategic planning of HRWM is to reduce waste generation and improve recycling channels, and align with the waste hierarchy. Hence, in HRWS, environmental directives are not just for WEEE but also include other common recyclates which should then be diverted from landfill back to the main channel at a certain recycling target required by EU member countries. According to a supply chain point of view, sustainability mainly focuses on triple bottom lines which include 3 strategic key issues (Economy, Environment and Social after Sarkis et al., 2010). The 3 strategic key issues are compatible to the $3 \mathrm{Rs}$ (reduce, reuse, and recycle) that manages backward flows in the supply chain management (SCM) and the management of backward flow using a simple 3Rs hierarchy of product disposition has similar characteristics of a reverse logistics (RL) system within the SCM (Stock and Mulki, 2009).

Empirically, RL has made many contributions to the social and economic sustainable impact by focusing on the closed-loop economy to divert waste from landfills (Christopher, 2011). RL has been considered as a green logistics approach in supply chain management that focuses on saving raw material and energy (McKinnon et al., 2012) within the forward logistics and within the backward movement, a reduction of usage in landfill capacity and efficient recovery of recyclates (Murphy and Poist, 2003). Recycling, in particular, has played a major role in variety means of product disposition (end-of-life, unwanted, obsolete, irreparable etc.) within Household Recycling Waste System (HRWS). The terms green and reverse logistics are interchangeably used in many logistics literature (McKinnon et al., 2012; Hazen, et al., 2011). Both green and reverse logistics constitute the nature of sustainability and to achieve such sustainability through RL is by recycling (McLeod et al., 2008). However, "green logistics" does not reflect the backward flow alone within HRWS. This is because this concept has a wider scope in SCM as described below:

Green logistics consists of all activities related to the eco-efficient management of the forward and reverse flows of products and information between the point of origin and the point of consumption whose purpose is to meet or exceed customer demand (Thiell et al., 2011: p.335)

Green logistics primarily focuses on the reduction of environmental impact and energy footprint from material handling, waste management, packaging and transport (McKinnon et al., 2012; Hazen et al., 2011). Therefore, in the perspective of HRWS, green logistics can basically be well explained as the awareness of municipalities on the environmental impact of the backward flow (RL) within HRWS (Thiell et al., 2011). The essence of reverse logistics lies within reclaiming the value of returnable and recyclates that are parallel to green logistics practices in SCM (Hazen et al., 2011). Furthermore, RL is considered as the fundamentals of "sustainable approach" by implementing an effective recycling system within HRWS (McLeod et al., 2008).

\subsection{Recycling is a reverse logistics of household recycling waste system}

This study is particularly concerned about one aspect of reverse logistics namely recycling. Recycling has been analyzed thoroughly as reverse logistics concept (Dowlatshahi, 2010; Carter and Ellram, 1998) which consequently brought up the development of many theoretical frameworks. Recycling can be defined as "A method of recovering waste as resources that include the collection, and often involving the treatment, of waste products for use as a replacement of all or part of the raw material in a manufacturing process (European Environment Agency, 2013 in Garechana et al., 2014).

Recycling is basically a reverse logistic option for retrieving product returns and waste to the forward channel by 'reuse, recycle and reduce' in managing the returnable, recyclates and waste (Stock, 1998). Guiltinan and Nwokoye's research had discovered that recycling played a major role in RL processes and there were three key areas (legislation, operation capabilities and marketing) with significant influences on the key performance of HRWM (1975). This also coincides with Carter and Ellram (1998) which addressed the effectiveness of RL framework based on those mentioned key areas. However, the latter authors are more concerned with RL framework at the pre and postconsumer waste in compared to Guiltinan and Nwokoye that is concerned on the post-consumer waste (1975).

Recycling is an important RL option as it is accountable for collection and processes consumable waste back to forward logistics to reduce the usage of virgin materials in mainstream production (Garechana et al., 2014). Take an example of De Brito's framework (2004) where the RL framework establishment includes recycling with its critical factors (actors, drivers, product, process) and expands the 
dimension of Carter and Ellram framework to a more practical approach in handling backward movement primarily in HRWM (in the following the HRWM only focusing on the post-consumer waste). Therefore, an establishment of efficient recycling system within HRWM may reduce waste disposal and diversion of the waste stream from the landfills (Deutz and Frostick, 2009).

In a nutshell, this study refers the HRWM as the supervised handling of waste material from generation at the source through the recovery processes up to disposal (OECD, 2008). In the UK, this definition refers to Local Authority Collected Municipal Waste (LACMW) that defines whether the waste collected by municipalities which originated from household or business waste which is collected by the local authority, they do carry similar aspect and composition required by the Landfill Directive (DEFRA, 2012).

\subsection{Symbiosis Effect}

The reverse logistics (RL) referred the situational factors in prior research as accessibility and availability that are similar to the HRWS. These operational/situational factors were found as strong predictors in prior research nonetheless, the aforementioned studies somewhat neglect the potential of interaction between the situational and behavioral aspects of RL (i.e. personal factors).

Despite the variety of theoretical approaches used in reverse logistics, little attention has been paid to the theorization of reverse logistics in HRWM particularly the interaction between HRWS and HRB (Jahre, 1995). In addition, underpinnings and knowledge lenses in reverse logistics flow (Carter and Ellram, 1998) still remain ambiguous as to how HRB and HRWS exactly interact with each other. The ambiguity of theoretical underpinning derived from the lack of theory within RL scopes (Dowlatshahi, 2000). Understanding such interactions, which might be conceived as a symbiosis effect, may help identify the effective ways of handling household waste issues and cultivating a more amicable attitude towards recycling on behalf of households.

The "symbiosis effect" proposed in this paper as a precondition (pre-cursor) phase requires a variety of conceptual lenses (theoretical frameworks and underpinnings) hence, requires an interdisciplinary approach for an empirical study (supported by Carter and Ellram, 1998).

Personal factors are influenced by values, culture, religion, education and income level, including working status or life experiences (Thogersen, 2006). Prior studies have shown that personal factors such as environmental attitude, perceived behaviour and personal capabilities tend to influence the household recycling level (Barr et al., 2013). In prior studies, personal factors such as working status and social norms toward situational factors were not conclusive evidence with regards to symbiosis effect (Keramitsoglou and Tsagarakis, 2013). Previous recycling studies mostly focus on either operational (situational factors after Woodard et al., 2006; Jahre, 1995) or purely behavioral (personal factors after Thogersen, 2006). Consequently, recycling studies conducted to determine the effects of a novel recycling design are normally unable to clarify the reason behind why and if such households' recycling attitude and behaviour have truly changed (Woodard et al., 2006; Lyas et al., 2005; Jahre, 1995). Woodard et al. (2006) study were concerned with the level of recycling rate before and after an introduction of recycling schemes whereby the finding did show a positive relationship between the facilitation of the recycling scheme with the participation of the selected residential.

Similarly, in Lyas et al., and Jahre, where in this study showed a positive change in the level of recycling participation when changes of a better or effective HRWS were introduced $(2005 ; 1995)$. However, whilst behavioral studies may provide a deep understanding of households' attitudes and behaviour, they seldom conceptualize the "precondition" aspects of HRWS which are required for HRB to be effectively manifested. According to norm-activation theory (Biel and Thogersen, 2007), individuals (living in a property) have certain beliefs and attitudes towards recycling and their recycling behaviour can be triggered by different stimuli from particular situational factors (effective facilities and services, consistent collection schedule, accessibility and availability as well as informative communication packs). This is considered as the "precondition" phase where the householders firstly have to undergo the process in order for HRB to be manifested effectively. Therefore, it is crucial for municipalities to engage with householders and to understand how different households react to certain situational factors.

The assumption is a cognition by which householders become accepting of recycling can be conceptualized as a symbiosis effect between householders and the local authority organizing the recycling system.

Symbiosis is an interaction between two different entities in close physical association, typically to the advantage of both, (Oxford Dictionaries, 2013). The key element from the Oxford definition of symbiosis is the element of interaction between two different entities. Whereby, the symbiosis effect suggested in this study is an interaction between situational and personal factors that are represented respectively by the HRWS from the municipalities and the household recycling behaviour (A Jalil et al., 2016). The symbiosis effect between the recyclers (householders) and providers (municipalities) instigates the recovery of materials which can ultimately re-enter the supply chain. If the householders respond positively to recycling systems, the municipalities may further refine them to achieve the next level of recycling rate.

\section{METHODOLOGY}

To realize the objectives of the undertaken study a mixed methodology approach is applied (Golicic and Davis, 2012). First to understand HRB in clearer perspectives (Park and $\mathrm{Ha}, 2014$ ) and second, addressing the multiple attributes by harmonizing the "facts". And aims which in turn projected more applicable methods to answer and realize the research questions and objectives. One of the problems with gaining insight into a symbiosis effect is complexity. Consequently, the approach is pluralistic and supported by our multi-disciplinary backgrounds.

This study applies the tradition of mixed methods within social and behavioral research in disagreement with mono-methodology approaches in answering the social phenomenon (Venkatesh et al., 2013; Golicic and Davis, 2012). By applying this methodology, it allows the meta- 
inferences between the richness of qualitative findings with the robustness of quantitative data. It gives the holistic dimension to clarify the social assumptions. Needless to say, this methodological approach supports innovative ways of looking at the research design and creating the triangular effect on confirming constructs, thus giving validity and reliability which are scarcely received in qualitative approach and a meaningful confirmatory resonance in quantitative approach (Mertens, 2014). A first phase is a qualitative approach that uses a qualitative inquiry: semistructured interviews based on the phenomenological method (Roulston, 2010). Whereby, a total of fourteen respondents participated in this study: in which two of those were local authority officers - one from the East Riding of Yorkshire and the other from the City of Hull. The remaining twelve respondents were demographically diverse and lived or used to live in the East Riding of Yorkshire and the City of Hull.

The geographic areas were evenly represented: seven were from the City of Hull and five from the East Riding of Yorkshire. The final sample included nine females and five males aged between $24-52$ years (mean age $=29$ ); students from the University of Hull who were recruited via convenience sampling. More females $(67 \%)$ than males $(33 \%)$ participated in the interviews. This was consistent with past research in recycling (Smith, 2009) which noted that women were more likely to participate in research where environmental issues were concerned. The respondents' recycling experience ranged from two to twenty years, with three of the respondents' announcing that they had been recycling way before recycling initiatives even started.

The study was advertised to students via a student portal and social media of relevant departments. Each conducted interview took approximately forty-five minutes to an hour. Upon arrival at the interview session, the respondent was given an information sheet for a brief demographic survey. The respondent was asked to provide his/her consent to participate verbally. The sessions were audio recorded and transcribed verbatim by the author and all identifying details were removed to maintain anonymity.

As for the second stage, the target population for this study consisted of residents from two municipal areas: the East Riding of Yorkshire and the City of Hull. The unit of analysis was the household. A postal survey questionnaire was sent to 500 households from each area. To accede the full impact of the low response rate associated with postal surveys, an online survey was published via the University of Hull's social media platforms, the local councils' affiliated community networks, public community online news network (e.g. 'this is Hull and East Riding') and under the discretion of selected companies within the population parameters (e.g. Kingston Communications, East Yorkshire Motor Services, and Jackson's).

\section{FINDINGS AND DISCUSSIONS}

The East Riding of Yorkshire Council (ERY) and the Hull City Council (Hull) are neighboring unitary LAs (i.e. responsible for waste collection and disposal) in the northeast of England.

ERY is a geographically diverse territory (comprising suburban and urban but substantially rural communities) averaging 134 people per square kilometer, in comparison to Hull (densely urban and suburban), which averages 3,146 people per square kilometer. However, the total population size is similar for both LAs: 325,000 in ERY, compared to 263,900 in Hull. Socially the two LAs are also quite distinct from each other and represent two distinct cases. According to the 2010 English Indices of Deprivations (DCLG, 2010), Hull has both a significantly higher proportion of its population classed as deprived, and a significantly larger proportion of its area containing a high proportion of deprived households (measured by indices including income, employment, health, education and housing).

These two contrasting LAs have co-operated on waste issues since their formation in 1996. They issued a joint waste management strategy in 1999 (Hull and ERY, 2004). With increasing prioritization of recycling, a joint sustainable waste management strategy appeared in 2006 (ERY and Hull, 2012) announcing plans for achieving a $45 \%$ recycling and composting rate. From 2000-01 to 2010-11 combined recycling and composting rates in these authorities followed the national improvement trajectory, albeit consistently below national average and ERY's rate is higher than Hull as shown in Figure 1. However, since then Hull has achieved the LAs' self-imposed target before ERY, and both LAs have consistently exceeded the national average rate since 2011.

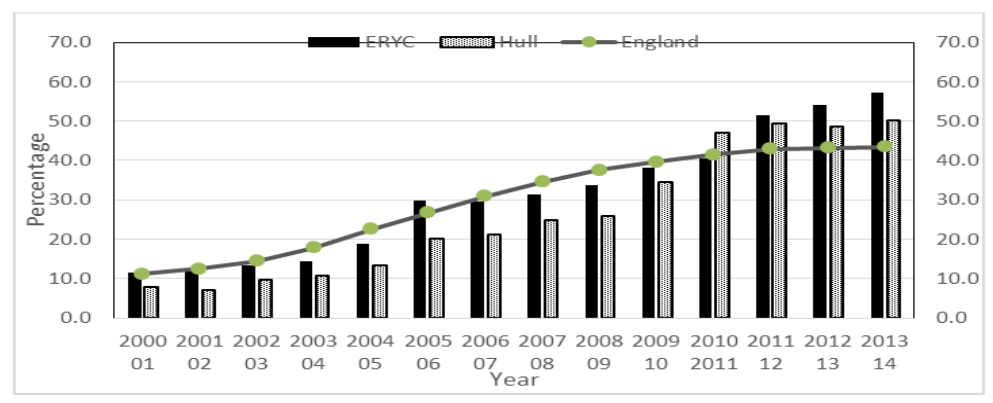

Figure 1. Percentage of Household Waste Recycled or Composted For the Two Local Authorities and an Average for England (DEFRA, 


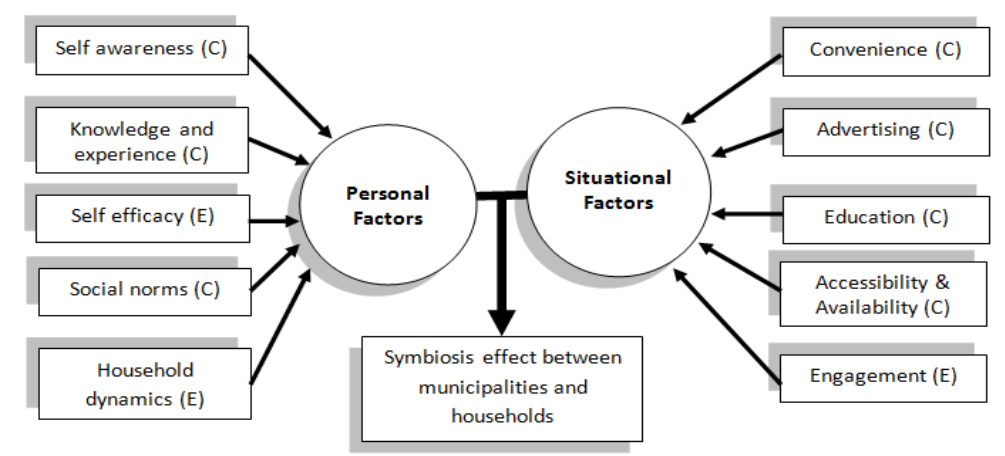

Figure 2. Thematic Analysis Network of Symbiosis Effect between Personal and Situational Factors

Table 1. Respondent demographic details $(\mathrm{N}=412)$

\begin{tabular}{|c|c|c|c|}
\hline Item & Frequency & & Percentage \\
\hline \multicolumn{4}{|l|}{ Age } \\
\hline 20 OR UNDER & 21 & \multirow{2}{*}{\multicolumn{2}{|c|}{$\begin{array}{r}5.1 \\
20.6\end{array}$}} \\
\hline $21-30$ & 85 & & \\
\hline $31-40$ & 96 & \multicolumn{2}{|r|}{23.3} \\
\hline $41-50$ & 59 & \multicolumn{2}{|r|}{14.3} \\
\hline 51 OR OLDER & 151 & \multicolumn{2}{|r|}{36.7} \\
\hline Total & 412 & \multicolumn{2}{|r|}{100} \\
\hline Item & Number & & Percentage \\
\hline \multicolumn{4}{|l|}{ Gender } \\
\hline Male & 157 & \multicolumn{2}{|r|}{38.1} \\
\hline Female & 255 & \multicolumn{2}{|r|}{61.9} \\
\hline Total & 412 & \multicolumn{2}{|r|}{100} \\
\hline Item & & Number & Percentage \\
\hline \multirow[t]{3}{*}{ Recycling Experience (years) } & More than 4 yrs. & 307 & 74.5 \\
\hline & Less than 4 yrs. & 105 & 25.5 \\
\hline & Total & 412 & 100 \\
\hline \multirow{3}{*}{$\begin{array}{l}\text { Living in current property } \\
\text { (years) }\end{array}$} & More than 4 yrs. & 286 & 69.4 \\
\hline & Less than 4 yrs. & 126 & 30.6 \\
\hline & Total & 412 & 100 \\
\hline
\end{tabular}

\subsection{First Phase of the Empirical Study}

The aim of the first inductive study phase was to explore the notion of a 'symbiosis effect' and intended to be both confirmatory and revelatory. The recycling experience of respondents ranged from two to twenty years, with three of the respondents reporting that they had been recycling before LA recycling initiatives started. The interviews were between 90 and 120 minutes long and digitally recorded, transcribed, and subsequently coded using NVivo software. Interviewing concluded in line with the principles of theoretical saturation (Lincoln and Guba, 2013), i.e., when addition interviews yielded no new insight. Themes were derived from a priori literature and thematic analysis of transcripts was used to confirm concepts drawn from literature, whilst also allowing new themes to emerge (Braun and Clarke, 2006). The most commonly occurring themes were taken forward.

\subsection{Second phase of the empirical study}

For the second deductive phase of research, the target population consisted of residents from the two LA areas investigated in the first phase, ERY and Hull, and the unit of analysis was the household. The total population of both of the LA's remit areas was 588,900 at the time of the survey (ERY, 2015; Hull, 2015). A postal survey questionnaire was sent to 500 households from each area (1000 in total), out of which 200 usable responses were received in total. In addition, to allow for the impact of low response rates normally associated with postal surveys, an online survey was also published via a social media platform. The affiliated community networks of the local municipalities are a customer engagement portal where customers can comment and interact with each other without close supervision). Selected local companies also distributed the survey for the attention of employees living in Hull or the East Riding. This provided an additional 212 responses for a total of 412 .

Table 1 provides a summary of the socio-demographic profiles of the respondents

The sample was slightly dominated by female respondents (approx. 62\%) and the majority of respondents fell within the 51 or older age group. Most respondents have more than four years of recycling experience (approx. 75\%) and had been living in the same property for more than four years $(69 \%)$. A frequency analysis showed that more than $90 \%$ of households were clearly aware of why they recycled. Many considered their motives for recycling as being grounded in a belief that recycling improved their environment and that they wanted to live in an environmentally conscious society.

The study considered the four situational factors (convenience; advertising and education; engagement; accessibility and availability) alongside personal factors for correlation and predictive values. The Pearson's correlation revealed the relationship between the convenience, engagement, and accessibility and availability (excluding advertising and education which showed a non-significant relation) with five demographic factors (age, employment, knowledge, experience and household dynamics) and a combination of three personal factors (self-awareness, self- 
efficacy and social norms). Items underlying the personal and situational factors were formed into relevant composite factors and then a statistical correlation was tested between these composite factors including all demographic items. Those representing a more than a 0.05 significance level were omitted from multiple regression analysis.

The correlation between these two composite factors is illustrated in Table 2. Results detailed in Table 2 reveal that personal factors have a significant relationship to situational factors $(\mathrm{p}<0.01)$ and vice versa; with a positive correlation $(\mathrm{r}(412)=+0.41)$. Four demographic items were also found to have a positive relation with both factors $(\mathrm{r}(412)>+0.10)$ and a correlation between composite personal factors with those four demographic items had a significant relationship $(\mathrm{p}<0.01)$. However, household employment has a significant influence at $(\mathrm{p}<0.01)$ on composite situational factors, thus the age of a household and household dynamics such as marital status were at a $(\mathrm{p}<0.05)$ significant level. 'Knowledge and experience' of recycling had no significant correlation with composite situational factors. The analyses indicated that a socio-demographic profile of a local constituent has a positive correlation with factors contributing to HRB.
Then the composite personal factors with the exception of personal knowledge and number of years from householder's recycling experience are extended to individual attributes of situational factors (engagement, convenience, accessibility and availability) (Table. 3). Individual knowledge and recycling experience are considered central components from personal attributes based on previous empirical studies on HRB (Woodard et al., 2006). The results showed that the personal factors had a significant relationship with engagement $(\mathrm{p}<0.01)$ with positive correlation $(\mathrm{r}(412)=+0.71)$; as well as convenience $(\mathrm{p}<0.01)$ with positive correlation $(\mathrm{r}(412)=+0.44)$ and accessibility and availability $(\mathrm{p}<0.01)$ with positive correlation $(\mathrm{r}(412)=+0.27)$. Similar to Kandulapati \& Bellamkonda work (2014), a service recovery is important when the applicable situational factors available to online buyers. Pearson's correlation analyses have revealed that personal factors have a strong positive relationship with engagement. An incremental change in engagement by the LAs will have a positive effect on the HRB (Kalamas et al., 2014) even though in the study we found a positive relationship between personal factors with convenience and accessibility and availability factors, but with rather a moderate and weak intensity.

Table 2. Correlation table I

\begin{tabular}{|c|c|c|c|c|c|c|}
\hline \multirow{2}{*}{ Factors } & \multicolumn{5}{|c|}{ PEARSON CORRELATION } & \multirow[t]{2}{*}{ Sig. (2-tailed) } \\
\hline & 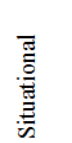 & $\underset{<0}{2}$ & 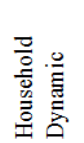 & 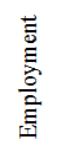 & 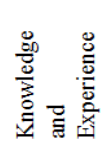 & \\
\hline $\begin{array}{l}\text { Personal } \\
\text { Situational }\end{array}$ & $\begin{array}{l}0.41 \\
1\end{array}$ & $\begin{array}{l}0.24 \\
0.10\end{array}$ & $\begin{array}{l}0.20 \\
0.12\end{array}$ & $\begin{array}{l}0.23 \\
0.17\end{array}$ & $\begin{array}{l}0.15 \\
\text { n.s }\end{array}$ & $\begin{array}{l}0.00 \\
0.01\end{array}$ \\
\hline
\end{tabular}

Table 3. Correlation table II

\begin{tabular}{|l|c|c|c|c|c|c|}
\hline \multicolumn{7}{|c|}{ Pearson's Correlation (Sig.) } \\
\hline $\begin{array}{c}\text { Item/factor } \\
(\mathrm{s})\end{array}$ & Personal & Engagement & $\begin{array}{c}\text { Knowledge } \\
\text { and } \\
\text { Experience }\end{array}$ & Convenience & $\begin{array}{c}\text { Accessibility } \\
\text { and } \\
\text { Availability }\end{array}$ & $\begin{array}{c}\text { Number Of } \\
\text { Years In } \\
\text { Recycling }\end{array}$ \\
\hline Personal & $1.000(0.00)$ & $0.705(0.00)$ & $0.767(0.00)$ & $0.441(0.00)$ & $0.272(0.00)$ & $0.113(0.01)$ \\
\hline $\begin{array}{l}\text { Knowledge } \\
\text { and } \\
\text { Experience }\end{array}$ & $0.767(0.00)$ & $0.596(0.00)$ & $1.000(0.00)$ & $0.382(0.00)$ & $0.381(0.00)$ & $0.019(0.01)$ \\
\hline $\begin{array}{l}\text { Number of } \\
\text { Years in } \\
\text { Recycling }\end{array}$ & $0.113(0.00)$ & $0.108(0.00)$ & $0.019(0.00)$ & $0.039(0.00)$ & $0.077(0.00)$ & 1.000 \\
\hline
\end{tabular}

This study employed multiple regression analysis for both factors and demographical items to understand more about the relation between predictor variables (situational) and a dependent or criterion variable (personal) as shown in Table 4. This analysis was relevant as it addressed the assessment of various relationships, using the information from independent variables to improve the accuracy in predicting values for the dependent variable (Green, 1991). The term 'mutually dependent' suggests either situational and / or personal factors can be either the dependent or independent variables respectively. In this study, both factors coded interchangeably between analyses both dependent and independent variables. When the coded personal factors as the dependent variable it is found that engagement $(\beta=+0.32$, $\mathrm{p}<0.01)$, convenience $(\beta=+0.16, \mathrm{p}<0.001)$, and accessibility and availability $(\beta=-0.13, \mathrm{p}<0.01)$ were significant predictors of recycling behaviour. 
The overall model fit was $r^{\wedge} 2=0.838$. The main effect of all situational factors was significant, $\mathrm{f}(5,406)=191.61$ MSE $=12.06, \mathrm{p}<0.01$ as shown in Table 5. The interaction of situational factors included the four demographic variables, with personal factors as dependent variable, is also significant when applying bivariate ANOVA as shown in Table 6: age $\mathrm{F}(1,410)=25.43, \mathrm{MSE}=37.78, \mathrm{p}<0.01$, marital status $\mathrm{F}(1,410)=16.58, \mathrm{MSE}=38.57, \mathrm{p}<0.01$, employment $\mathrm{F}(1,410)=22.86, \mathrm{MSE}=38.01, \mathrm{p}<0.01$ and number of year recycling $\mathrm{F}(1,410)=10.01, \mathrm{MSE}=39.17$, $\mathrm{p}<0.01$.

In this bivariate model the analysis was extended to seek interaction between these two factors. Thus, the dependent variable (personal factors) is highly dependent on situational factors for HRB to progress positively.

Table 4. Model coefficients

\begin{tabular}{l|lllll}
\hline \multirow{2}{*}{ Model 1 } & \multicolumn{2}{l}{$\begin{array}{l}\text { Unstandardized } \\
\text { Coefficients }\end{array}$} & $\begin{array}{l}\text { Standardized } \\
\text { Coefficients }\end{array}$ & $T$ & Sig. \\
\cline { 2 - 4 } & $\mathrm{B}$ & Std. Error & Beta & & \\
(Constant) & 15.093 & 1.851 & & 8.154 & 0.000 \\
Engagement & 0.316 & 0.032 & 0.359 & 9.890 & 0.000 \\
Convenience & 0.156 & 0.048 & 0.106 & 3.225 & 0.001 \\
Accessibility and & -0.125 & 0.031 & -0.126 & -3.994 & 0.000 \\
Availability & & & & & \\
\hline
\end{tabular}

Table 5. Model fit and univariate ANOVA

\begin{tabular}{|l|l|r|r|r|r|r|}
\hline Model & Rodel Summary & \multicolumn{1}{c|}{$\begin{array}{c}\text { Adjusted } \\
\text { R Square }\end{array}$} & $\begin{array}{c}\text { Std. Error of the } \\
\text { Estimate }\end{array}$ \\
\hline 1 & 0.838 & R Square & & \multicolumn{1}{c|}{3.473} \\
\hline \multicolumn{7}{|c|}{ ANOVA } \\
\hline Model & & Sum of Squares & Df & Mean Square & F & Sig. \\
\hline 1 & Regression & 11555.827 & 5 & 2311.165 & 191.607 & 0.000 \\
& Residual & 4897.171 & 406 & 12.062 & & \\
& Total & 16452.998 & 411 & & & \\
\hline
\end{tabular}

Table 6. Multiple regression bivariate ANOVA

\begin{tabular}{|c|c|c|c|c|c|c|}
\hline \multicolumn{7}{|c|}{ ANONA } \\
\hline & Model & Sum of Squares & $\mathrm{df} f$ & $\begin{array}{l}\text { Mean } \\
\text { Square }\end{array}$ & $F$ & Sig. \\
\hline \multirow{4}{*}{1} & $\begin{array}{l}\text { Regression } \\
\text { Residual (age) } \\
\text { Total }\end{array}$ & $\begin{array}{r}960.799 \\
15492.199 \\
16452.998\end{array}$ & $\begin{array}{r}1 \\
410 \\
411\end{array}$ & $\begin{array}{r}960.799 \\
37.786\end{array}$ & 25.427 & 0.00 \\
\hline & $\begin{array}{l}\text { Regression } \\
\text { Residual (marital status) } \\
\text { Total }\end{array}$ & $\begin{array}{r}639.494 \\
15813.503 \\
16452.998\end{array}$ & $\begin{array}{r}1 \\
410 \\
411\end{array}$ & $\begin{array}{r}639.494 \\
38.570\end{array}$ & 16.580 & 0.00 \\
\hline & $\begin{array}{l}\text { Regression } \\
\text { Residual (employment) } \\
\text { Total }\end{array}$ & $\begin{array}{r}868.746 \\
15584.252 \\
16452.998\end{array}$ & $\begin{array}{r}1 \\
410 \\
411\end{array}$ & $\begin{array}{r}868.746 \\
38.010\end{array}$ & 22.855 & 0.00 \\
\hline & $\begin{array}{l}\text { Regression } \\
\text { Residual (num. year } \\
\text { recycling) } \\
\text { Total }\end{array}$ & $\begin{array}{r}391.910 \\
16061.087 \\
16452.998\end{array}$ & $\begin{array}{r}1 \\
410 \\
411\end{array}$ & $\begin{array}{r}391.910 \\
39.173\end{array}$ & 10.005 & 0.002 \\
\hline
\end{tabular}

\section{CONCLUSION}

Recycling and RL have been co-examined in a small number of studies. To date, the studies in core Supply Chain Management journals have examined RL in the context of recovering and recycling plastics, (Bing et al., 2014), household medicines (Xie and Breen, 2014) and hospital waste (Ritchie et al., 2000). This study has therefore provided a contribution to the previously underexplored context of RL and recycling, more specifically to the context of LA or municipal RL channels and HRWS. This study, therefore, should have an interdisciplinary interest in both the SCM and waste management scholars. From a practical perspective, the findings should inform RL-HRWS design by LAs and municipalities looking to more effectively manage MSW and enhance recycling and sustainability. Waste collection is one of the most visible and universal of local authority services: improving the relationship between service user and service provider is to the mutual satisfaction of both. RL practitioners should introduce systems to support the recovery of MSW in sympathy with communication and education initiatives to affect HRB and should also appreciate a symbiosis effect in the design of HRWS.

The findings also suggest there can be profound social implications for improved recycling performance in LAs; even incremental improvements in HRWS performance can lead to enhanced sustainability through higher recycling rates, reduced MSW diversion to landfill, decreased 
pollution levels, reduced carbon footprints, and reduced depletion of scarce natural resources. Consideration of a symbiosis effect, and the situational and personal factors proposed in this paper would be of particular value to practitioners when attempting to move from one mode of waste collection (i.e. co-mingled) to another which requires a greater commitment by a household at the pivot point (i.e. source separation). For RL channel design the paper has provided a strong foundation for the consideration of a symbiosis effect by channel designers. The principle of a symbiosis effect should also be examined with respect to other policy areas (e.g., transportation) where public engagement with policy is important.

\section{ACKNOWLEDGEMENT}

The study was under scholarship of the Malaysia Ministry of Education for Higher Education. This empirical work is supervised by Prof David B Grant, Dr. Pauline Deutz of University of Hull and Dr. John D Nicholson of Sheffield Hallam University.

\section{REFERENCES}

A Jalil, E. E., Grant, D. B., Nicholson, J. D., \& Deutz, P. (2016). Reverse logistics in household recycling and waste systems: a symbiosis perspective. Supply Chain Management: An International Journal 21(2), pp. 245258.

Abbasi, M. \& Nilsson, F. (2012). Themes and challenges in making supply chains environmentally sustainable. Supply Chain Management: An International Journal 17(5), pp. 517-530.

Abbott, A., Nandeibam, S. and O'Shea, L. (2011). Explaining the variation in household recycling rates across the UK. Ecological Economics 70(11), pp. 22142223.

Barba-Gutiérrez, Y., Adenso-Diaz, B. \& Hopp, M. (2008). An analysis of some environmental consequences of European electrical and electronic waste regulation. Resources. Conservation and Recycling 52(3), pp. 481495.

Barr, S., Guilbert, S., Metcalfe, A., Riley, M., Robinson, G. M. \& Tudor, T. L. (2013), Beyond recycling: An integrated approach for understanding municipal waste management. Applied Geography, 39, pp.67-77.

Biel, A. \& Thøgersen, J. (2007), Activation of social norms in social dilemmas: A review of the evidence and reflections on the implications for environmental behaviour. Journal of Economic Psychology, 28(1): pp. 93-112.

Bing, X., Bloemhof-Ruwaard, J.M. and van der Vorst, J.G.A.J. (2014), Sustainable reverse logistics network design for household plastic waste. Flexible Services and Manufacturing Journal, 26(1-2), pp. 119-142.

Braun, V. and Clarke, V. (2006), Using thematic analysis in psychology. Qualitative Research in Psychology, 3(2), pp. 77-101.

Caplice, C. and Sheffi, Y. (1994), A Review and Evaluation of Logistics Metrics. The International Journal of Logistics Management, 5(2), pp. 11-28.
Carter, C. R., \& Ellram, L. M. (1998). Reverse logistics: a review of the literature and framework for future investigation. Journal of business logistics, 19(1), pp. 85.

Cherrett, T., Maynard, S., McLeod, F. \& Hickford, A. (2010), Reverse logistics for the management of waste. McKinnon, et al. (eds.), No.242.

Christopher, M. (2011), Logistics and Supply Chain Management (4 edn.), FT Press.

Creswell, J.W. (2008), Research design: Qualitative, quantitative, and mixed methods approaches, Sage Publications.

DCLG (2010), Department of Communities and Local Government English Indices of Deprivation., https://www.gov.uk/government/statistics/englishindices-of-deprivation-2010.

De Brito, M. P. \& Dekker, R. (2004), A framework for reverse logistics. Reverse Logistics. Springer Berlin Heidelberg, pp. 3- 27

DEFRA. (2012), 'Waste and Recycling' Available at: <www.defra.gov.uk/statistics/environment/waste/>. (accessed 12.08.2014).

DEFRA. (2014). DEFRA. Statistics on waste managed by local authorities in England in 2013-2014 Retrieved 27 September 2015, from https://www.gov.uk/government/uploads/system/uploa ds/attachment_data/file/375945/Statistics_Notice_Nov _2014_Final_3_.pdf

Deutz, P. and Frostick, L.E. (2009), Reconciling policy, practice, and theorisations of waste management. The Geographical Journal, 175(4), pp. 247-250.

Dimitrova, E. (2014), The 'sustainable development' concept in urban planning education: lessons learned on a Bulgarian path. Journal of Cleaner Production, 62, pp. 120-127.

Dowlatshahi, S. (2000), Developing a theory of reverse logistics. Interfaces, 30(3), pp.143-155.

ERY (2015) East Riding of Yorkshire Council bins and collections,

http://www2.eastriding.gov.uk/environment/binsrubbish-recycling/bins-and-collections/blue-bin/.

ERY and Hull (2012), Target 45 + Joint Sustainable Waste Management Review. East Riding of Yorkshire Council and Hull City Council.

Garechana, G., Rio-Belver, R., Cilleruelo, E. \& GavilanesTrapote, J. (2014), Capturing waste recycling science. Technological Forecasting and Social Change, 81, pp. 250-258.

Golicic, S. \& Davis, D. F. (2012), Implementing mixed methods research in supply chain management. International Journal of Physical Distribution \& Logistics Management, 42(8), pp. 2-2.

Grant, D.B., Trautrims, A. and Wong, C.Y. (2015), Sustainable logistics and supply chain management: principles and practices for sustainable operations and management (revised edition), Kogan Page.

Green, S.B. (1991), How many subjects does it take to do a regression analysis? Multivariate Behavioral Research, 26(3), pp. 499

Guiltinan, J. P. \& Nwokoye, N. G. (1975), Developing distribution channels and systems in the emerging recycling industries. International Journal of Physical Distribution \& Logistics Management, 6(1), pp. 28-38. 
Hazen, B. T., Cegielski, C., \& Hanna, J. B. (2011). Diffusion of green supply chain management: Examining perceived quality of green reverse logistics. The International Journal of Logistics Management, 22(3), pp. 373-389.

Hull (2015), Hull City Council waste and recycling bins, http://www.hullcc.gov.uk/portal/page?_pageid=221,72 0616\&_dad=portal\&_schema=PORTAL.

Hull and ERY (2004), Joint Waste Local Plan. Kingston upon Hull City Council and East Riding of Yorkshire Council,

file:///C:/Users/ggspd/Downloads/Joint\%20Waste\%20 Local\%20Plan.pdf.

Jahre, M. (1995), Household waste collection as a reverse channel - A theoretical perspective. International Journal of Physical Distribution \& Logistics Management, 25(2), pp. 39-39.

Kalamas, M., Cleveland, M. and Laroche, M. (2014), Proenvironmental behaviors for thee but not for me: Green giants, green Gods, and external environmental locus of control. Journal of Business Research, 67(2), pp. 1222.

Keramitsoglou, K.M. and Tsagarakis, K.P. (2013), Public participation in designing a recycling scheme towards maximum public acceptance. Resources Conservation and Recycling, 70, pp. 55-67.

Kandulapati, S., \& Bellamkonda, R. S. (2014). Examining the structural relationships of service recovery, customer satisfaction and image in online retailing. Operations and Supply Chain Management, 7(2), pp. 70-78.

Large, R. O., Kramer, N. \& Hartmann, R. K. (2013), Procurement of logistics services and sustainable development in Europe: Fields of activity and empirical results. Journal of Purchasing and Supply Management, 19(3), pp. 122-133.

Lincoln, Y.S. and Guba, E.G. (2013), The Constructivist Credo, Left Coast Press.

Lyas, J. K., Shaw, P. J. \& van Vugt, M. (2005), Kerbside recycling in the London Borough of Havering: progress and priorities. Resources, Conservation and Recycling, 45(1), pp. 1-17.

Mayers, K. \& Butler, S. (2013), Producer Responsibility Organizations Development and Operations. Journal of Industrial Ecology, 17(2), pp. 277-289.

McKinnon, A., Browne, M. \& Whiteing, A. (2012), Green logistics: Improving the environmental sustainability of logistics, Kogan Page Publishers.

McLeod, F., Hickford, A., Maynard, S., Cherrett, T. \& Allen, J. (2008), Developing innovative and more sustainable approaches to reverse logistics for the collection, recycling and disposal of waste products from urban centres. Green Logistics Report, University of Southampton (www. greenlogistics. org).

Mishra, N., Kumar, V., \& Chan, F. T. S. (2012). A multiagent architecture for reverse logistics in a green supply chain. International Journal of Production Research, 50(9), pp. 2396-2406.

Murphy, P. R. \& Poist, R. F. (2003), Green perspectives and practices: a comparative logistics study. Supply Chain Management: An International Journal, 8(2), pp. 122131.
OECD (2008), Household Behaviour and the Environment: Reviewing the Evidence. OECD.

Office of National Statistic. (2013), 'Population' Available at:

<http://www.ons.gov.uk/ons/taxonomy/index.html?ns cl=Population>. (accessed September 2011).

Oxford Dictionaries (2013), Symbiosis. Oxford University Press.

Park, J. and Ha, S. (2014), Understanding consumer recycling behavior: combining the theory of planned behavior and the norm activation model. Family and Consumer Sciences Research Journal, 42(3), pp. 278291.

Pohlen, T. L., and Farris, M. T. (1992), Reverse logistics in plastics recycling. International Journal of Physical Distribution \& Logistics Management, 22(7), pp. 3547.

Ritchie, L., Burnes, B., Whittle, P., and Hey, R. (2000), The benefits of reverse logistics: the case of the Manchester Royal Infirmary Pharmacy. Supply Chain Management: An International Journal, 5(5), pp. 226234.

Rogers, D. S., \& Tibben- Lembke, R. (2001). An examination of reverse logistics practices. Journal of Business Logistics, 22(2), 129-148.

Sarkis, J., Helms, M. M. \& Hervani, A. A. (2010), Reverse logistics and social sustainability. Corporate Social Responsibility and Environmental Management, 17(6), pp. 337-354.

Smith, W.G. (2008), Does gender influence online survey participation? A record-linkage analysis of university faculty online survey response behavior. Eric Document ED501717. Retrieved December, Vol. 31, No. 2009.

Stock, J. R. (1997), Applying theories from other disciplines to logistics. International Journal of Physical Distribution \& Logistics Management, 27(9/10), pp. 515-539

Stock, J. R. \& Mulki, J. P. (2009), Product returns processing: an examination of practices of manufacturers, wholesalers/distributors, and retailers. Journal of Business Logistics, 30(1), pp. 33-52.

Thiell, M., Zuluaga, J. P. S., Montañez, J. P. M. \& van Hoof, B. (2011), Green Logistics: Global Practices and their Implementation in Emerging Markets Green Finance and Sustainability: Environmentally-Aware Business Models and Technologies, pp. 334.

Thogersen, J. (1994), A model of recycling behaviour, with evidence from Danish source separation programmes. International Journal of Research in Marketing, 11(2), pp. 145-163.

Toffel, M. W. (2003). The growing strategic importance of end-of-life product management. California Management Review, 45(3), pp. 102-129.

Wiard, M.L. and Sopko, B.G. (1991), Recycling Basics: A Positive Waste Management Alternative for Ohio, $\mathrm{OH}$ Department of Natural Resources, Division of Litter Prevention and Recycling, Columbus, $\mathrm{OH}$.

Woodard, R., Harder, M.K., and Bench, M. (2006), Participation in curbside recycling schemes and its variation with material types. Waste Management, 26(8), pp. 914-919. 
Wright, R. E., Richey, R. G., Tokman, M., \& Palmer, J. C. (2011). Recycling and reverse logistics. The Journal of Applied Business and Economics, 12(5), pp. 9.

Xie, Y. and Breen, L. (2014), Who cares wins? A comparative analysis of household waste medicines and batteries reverse logistics systems. Supply Chain Management; an International Journal, 19(4), pp. 455474.

Emy Ezura A Jalil is a full time lecturer at School of Technology Management and Logistics, University of Utara Malaysia. Her research interest includes ethical issues in end-users relationships in reverse and green logistics. Other research interest will be individual dynamic and team culture in logistics chain and also humanitarian, event and Halal logistics management. Methodological interest is using mixed-methodology in multidisciplinary/interdisciplinary research. 